\title{
Kepler, Galileo and the birth of modern astronomy
}

\author{
Owen Gingerich
}

Harvard-Smithsonian Center for Astrophysics,

Science Center 371, Cambridge, MA 02138, USA

email: ginger@cfa.harvard.edu

\begin{abstract}
The International Year of Astronomy marks the 400th anniversary of Kepler's Astronomia nova and the first use of the telescope for astronomy, most notably leading to Galileo's Sidereus nuncius (1610). Kepler's book for the first time argued strongly for a physical basis to astronomical explanations. Galileo's work showed that a coherent understanding was more important for scientific progress than specific proofs. The efforts of both astronomers undermined the traditional geocentric cosmology and essentially brought about the birth of modern astronomy.
\end{abstract}

Keywords. Kepler, Galileo, ellipse, telescope, Astronomia nova, Sidereus nuncius

\section{Introduction}

2009 was chosen as the International Year of Astronomy in part because of two highly significant 400th anniversaries that mark the birth of modern astronomy: Johannes Kepler's Astronomia nova, and the first astronomical use of the newly invented telescope, which led to Galileo Galilei's Sidereus nuncius or Starry Messenger.

\section{Kepler: giving astronomy a physical basis}

Kepler's appropriately titled Astronomia nova or New Astronomy is a classic that stands in the triumvirate of key books for the astronomical revolution, alongside Copernicus' De revolutionibus and Newton's Principia mathematica philosophiænaturalis. Of these three books, it is probably the most misunderstood. Students learn that this book contains Kepler's first law, the elliptical shape of planetary orbits, and they typically are shown an illustration of a highly elliptical ellipse. Naturally they wonder, at least subliminally, why no one noticed such an obvious thing centuries earlier. But is was not as obvious as most textbooks suggest.

Ellipses have two related properties, eccentricity (the distance of the foci from the center of the ellipse), and ellipticity (the amount the figure bows in, deviating from a circle). From ancient times planetary orbits always had eccentricity, that is, the earth in the geocentric Ptolemaic cosmology was never at the precise center of the planetary circles†.

In Copernicus' famous diagram of his heliocentric system, it looks as if circles accurately centered on the sun are involved; in reality, his diagram shows zones in which the eccentric planetary paths are located. Kepler, for the first time in history, treated planetary orbits that have ellipticity as well as eccentricity. But this bowing of the orbit

$\dagger$ As a point of full disclosure, we must admit that some Islamic models tried to have the main planetary circles completely centered on the earth, but this was accomplished only by arranging auxiliary circles to give the planet what in essence amounted to an eccentric orbit. 
is almost subliminal. It barely shows on a Martian ellipse drawn on an ordinary sheet of letter paper, where the difference between a circle and an ellipse is scarcely more than the width of the pencil line. Even Kepler's own drawing in the Astronomia nova, depicting his triangulation that showed a considerable deviation from a circle, is actually a bit of advertizing hyperbole. So finding the ellipse was a great deal harder than meets the eye in most textbooks. It was only possible because Kepler got access to the incomparable data bank provided by the persistent naked-eye observations of Tycho Brahe, with their unprecedented accuracy.

Tycho's Martian observations were particularly concentrated around the times of opposition, that is, when Mars was directly opposite the Sun in the sky. The oppositions occurred about every two years -actually two months short of that, which means that the positions of succeeding oppositions regress around the sky in about 15 years. Kepler realized that if an opposition is well determined, then Mars' position with respect to the Sun is automatically established and the position of the Earth no longer matters. He thus used these oppositions to devise a procedure to compute the heliocentric longitudes of Mars with an accuracy spectacularly better than had hitherto been achieved. But nevertheless, when he computed the Martian latitudes (the angular distance North or South of the ecliptic circle), the procedure failed.

"Who would have believed it?" Kepler wrote. "The hypothesis, in such good agreement with the oppositions, is nevertheless false!" His predecessors -both Ptolemy and Copernicus- had not been bothered about using two different orbits for each planet, one for finding longitudes and a different one for finding latitudes. But Kepler, as a physical realist, felt strongly that a true orbit for Mars must correctly handle both longitudes and latitudes. No such fictional model building (or "instrumentalism") for him!

In the Astronomia nova Kepler leaves the problem unfinished and turns next to the orbit of the earth, the key to a deeper astronomy as he puts it. For years scholars thought that the Astronomia nova was a rambling autobiographical account of how he engaged in his warfare on Mars, especially because he interspersed such charming chapters as one entitled, On the occasion when I encountered the theory of Mars. I was very curious about some aspects of the presentation in his book, and for five years I persistently sought a microfilm copy of his Mars manuscripts preserved in Leningrad. Finally the Soviet authorities acceded to my pleas and provided an excellent microfilm. As I worked through the many pages of his Mars notebook, I realized that typically Kepler was working on many different aspects at the same time, and that the Astronomia nova itself spares us many of the side tracks and dead ends strewn in his path.

A problem of the Earth's orbit as presented in Copernicus' De revolutionibus had long perplexed Kepler. Did the earth, whose orbit was slightly off-center in his system, move around its orbit with a constant speed? According to Copernicus, the answer was yes, something that bothered Kepler, ever the physical realist. If the Sun was the source of the Earth's annual movement around the Sun, it should go faster when it was closer to the Sun. At the critical point in Kepler's own copy of Copernicus' book, there is a marginal note written by his teacher, Michael Maestlin, so obviously the two of them must have sat together discussing the way Copernicus handled the Earth's orbit. According to Copernicus, all of the planets except the Earth moved faster the closer they were to the sun in their eccentric orbits. Unlike virtually all other astronomers, Kepler was determined to link physical causes to the planetary motions, and he believed that some motive power emanating from the Sun propelled the planets in their orbits. Mercury went around the Sun the fastest because it was closest to the Sun. Distant Jupiter moved more slowly, and still more distant Saturn was even slower. Surely the Earth should move more swiftly in its orbit when it was closer to the Sun, just as the other planets did. If so, 


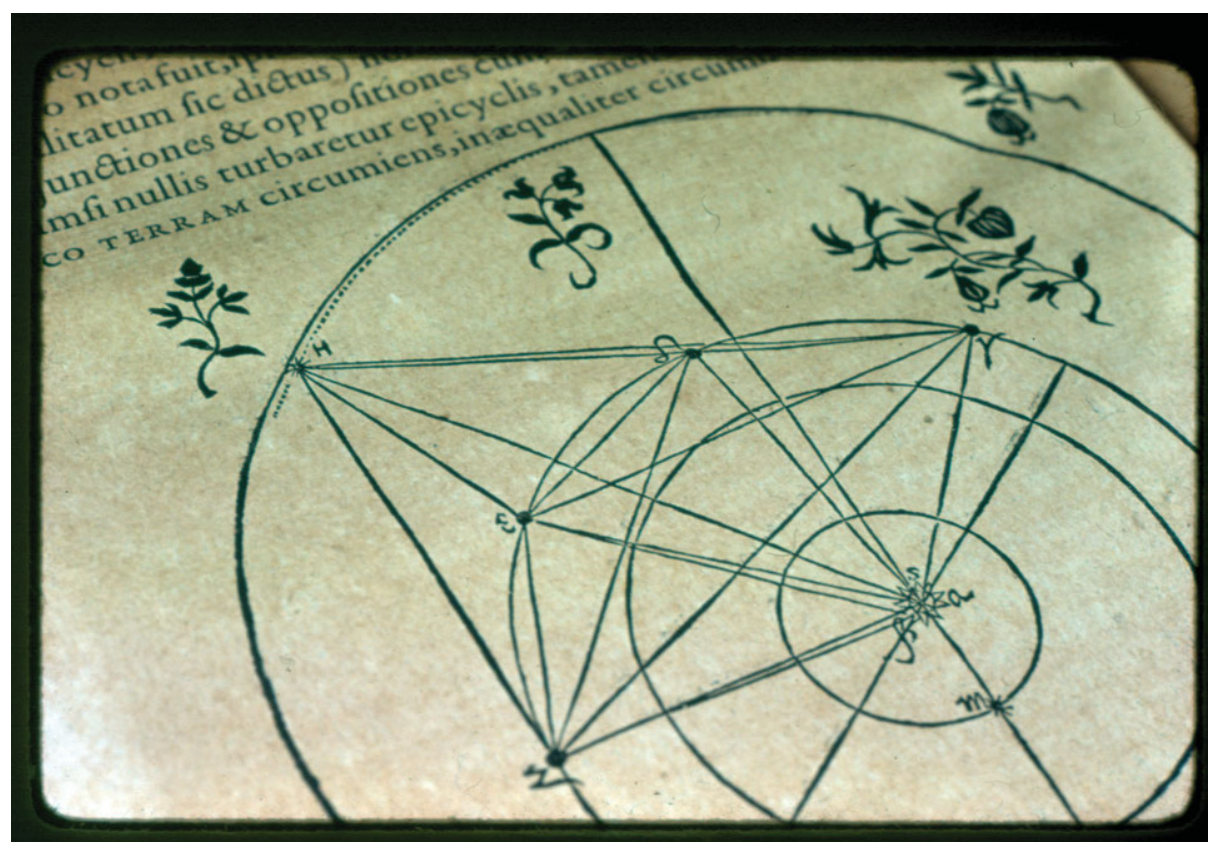

Figure 1. Kepler's key triangle for Mars in the Astronomia Nova (1609).

this required adjusting the position of the Earth's orbit, as Kepler must have suspected already while he was a student of Maestlin's at the University of Tübingen.

This section of Kepler's treatise is subtitled, A key to a deeper astronomy, and here first appears the famous picture of his triangulation to Mars, accomplished by finding successive directions to Mars when the ruddy planet has cycled back to its original position while the Earth has revolved more than once, to a different vantage point (see Figure 1). Because Kepler specifically places Mars off its circular orbit, the casual browser will assume that Kepler is about to map out the deviations of Mars from a circular path, and that the key to a more profound astronomy is the ellipse. Wrong! This section of the book was actually written well before he had stumbled onto the elliptical path, and its goal is not to find the path of Mars but the path of the Earth. Kepler hoped to deduce the changing distance of the earth from the Sun directly, by measuring the increasing apparent size of the Sun as the Earth drew closer, but alas, the effect was too subtle to be convincing. So the more delicate triangulation led the way, and behold! the eccentricity of the Earth's orbit, as found by Copernicus and more accurately determined by Tycho Brahe, had to be halved. (The technical expression in the literature is bisection of the eccentricity.) This maneuver, halving the eccentricity, now resolved the difficulty with respect to the discrepant latitudes of Mars, but left a small residual problem with some of the heliocentric longitudes. While really huge discrepancies - up to five degrees- had plagued both Ptolemy's and Copernicus' predictions, Kepler's revised orbit was always better than half a degree. Kepler preferred to give the number in heliocentric angles rather than the geocentric angles observed from Earth; seen from the Sun the maximum error was $8^{\prime}$. He liked to say that God had given him such a precise observer in Tycho Brahe that those small deviations could not be ignored. "The entire reformation of astronomy hinged on those eight minutes of arc", he declared.

Did Kepler now renew his triangulation effort to trace out the path of Mars? Popular accounts to the contrary, it was neither triangulation nor curve fitting that led to the 
ellipse. No, the deviations were much too subtle for that. Kepler was groping in the dark for a physical principle to g uide him, and what he intuitively hit upon was the law of areas, or as we now know, the powerful equivalent of the conservation of angular momentum. He saw that such a relationship worked perfectly at the near and far points on an orbit, but it was only his uncanny sense of the rightness of things that he gambled it should work at other points as well. Newton would be unimpressed. He sniffed that "Kepler guessed it, but I have proven it".

What Kepler did was to track the motion all the way around the orbit, tediously, a degree at a time. It was here that he stumbled onto using areas as a shortcut. Geometrically it made no sense at all, but it seemed to work. "Behold, a miracle!" he exclaimed, and he made little further effort to justify it. However, as he worked around the circle, he got too much area. He tried various orbits that bowed in to produce less area, and at the same time he tried to motivate the curves with complicated physical arguments. Ultimately he had to concede that these hypotheses "went up in smoke". At last he realized that an ellipse (which he had been using as an approximating figure) gave just the right area if he placed the sun at one focus of the ellipse. It was as if another miracle had occurred, and Kepler himself said it was like awakening from a deep sleep. And he managed to find a somewhat persuasive physical explanation involving magnetic attraction and repulsion. The physics was ultimately wrong. It could hardly be otherwise, for he did not yet appreciate the principle of inertia. But the important point was that Kepler's belief in the significance of having a physical explanation paved the path to Newton and his physics.

Kepler was not particularly pleased when his correspondent David Fabricius found a way to represent Tycho's observations simply with circles. Kepler exploded. "Your theory, born of mother geometry, is a mischievous whore", he wrote. "It will seduce many from my beautiful daughters born of mother physics". Later, Kepler's former mentor, Michael Maestlin, advised him to forget about physics, and just use geometry for astronomical problems, as had been the tradition since Greek times. Fortunately Kepler ignored both Fabricius and Maestlin. Kepler's truly distinguished contribution, transcending even his own impressive discoveries of the elliptical orbits and the law of areas, was his insistence on an astronomy based on causes, or celestial physics. This became the subtitle of his Astronomia nova, and his legacy. It was his great gift to the birth of modern astronomy.

\section{Galileo: overthrowing geocentric cosmology}

Far to the south of Prague, in what is today Italy but what was then a patchwork of city states, a little known astronomer was on the cusp of great fame: Galileo Galilei. Kepler had actually heard of Galileo, since just over a decade earlier, when Kepler was still a provincial high school teacher and Galileo was already a university astronomy professor, he had sent to Italy two copies of his Mysterium cosmographicum (the first enthusiastic Copernican treatise since De revolutionibus itself). His friend who had carried the books had inquired as to who might be interested in them and thus the little volumes found their way to Galileo, who promptly replied to Kepler that he, too, was a Copernican, albeit secretly. Kepler wrote back, urging Galileo to stand forth publically in favor of the heliocentric cosmology, but Galileo held his peace and did not reply.

By 1609 Kepler had become Imperial Mathematician to Emperor Rudolph II and had a distinguished publication record. Galileo, then aged 45, had published two rather modest books and was augmenting his professorial salary by marketing a pair of mathematical rulers that he had devised. He was a feisty debater, he had a mistress and three children, and he had advised the Venetian senators on certain fortifications, but his reputation 
was not widespread. At the end of 1609 and the first few weeks of 1610, however, Galileo made a pair of discoveries that changed him from a timid Copernican into an enthusiastic one, and which catapulted him into international fame.

In the summer of 1609 Galileo learned that a Dutch spectacles maker had invented a device with two lenses that brought distant images closer. Galileo quickly discovered how it had been done, and then went to work to improve its magnifying capabilities. By the end of August he could show the Venetian senators an 8-power spyglass, and by the middle of autumn he had achieved 20 power. He had essentially converted a carnival toy into a scientific instrument. Precisely when he first turned his new discovery machine to the heavens is unknown, but by November 30 he prepared himself with a sheet of special watercolor paper, brushes, and ink to record his observations of the Moon. He must also have found a way to steady the telescope, with its very narrow field of view. We wish we knew how he did it, but there is no information on record.

Now Galileo's prior art training, and his familiarity with light and shadows, was essential, for he realized immediately the significance of the tiny points of light alongside the fully illuminated part of the crescent Moon (see Figure 2). They were surely mountain peaks just catching dawn's light at lunar sunrise. Mountains!? Contrary to traditional belief, the Moon was not a perfectly smooth crystalline sphere. It was, in a word, earthlike. Throughout the next few weeks Galileo added further images to his sheet as the Moon waxed and waned. He saw mountains and plains, large flat areas like seas, and fields of peculiar round craters. But always there was his remarkable insight: the Moon was not just an ethereal, smooth ball, but it was earthlike in its nature.

If this was not quite enough to convert him into an enthusiastic Copernican, another astonishing discovery awaited him a month later, in January of 1610 . The gibbous Moon was only a few degrees from Jupiter, so Galileo may well have looked at the Moon and then turned to the bright planet. What surprised him was not so much that Jupiter was between three small stars, but that the stars were in a straight line, along the ecliptic path of the planets. Two were to the east, and one was to the west of Jupiter. Led by what fates he knew not, he tells us, Galileo took another look the next night, and was somewhat puzzled that the small stars were all on the western side of the planet. He thought he knew which way the planet was moving, but maybe he didn't remember exactly what he had seen the previous day. The next night, when he wanted to check again, was cloudy, but on January 10 only two little stars could be seen, both East of Jupiter†. Within a few days, and with mounting excitement, he discovered that there were actually four of the little stars, and they weren't stars -they were little planets accompanying Jupiter as it moved in the skył. The log sheet was becoming the most exciting single manuscript leaf in the long history of astronomy.

Promptly after Galileo understood that the little dots of light were not fixed stars, but moons of Jupiter, the language on his log sheet changed. He switched from Italian to Latin. Why? Latin was the international scientific language, and Galileo knew that he had international news. But he noticed something else: he realized that he had a remarkable naming opportunity. He had long yearned for a position at the court of Cosimo de Medici, the young archduke in Galileo's native Tuscany. By naming the newfound satellites the Medicean Stars, Galileo could surely win a courtly position in Florence. In a desperate hurry, lest he be scooped by someone else with a telescope, Galileo rushed into print. His Sidereus nuncius or Starry Messenger was illustrated and printed within two months of

$\dagger$ At this point he decided he had better keep a log book, so in it he sketched where he remembered the stars had been.

$\ddagger$ Only later would Kepler come up with the word 'satellites' to categorize them. 


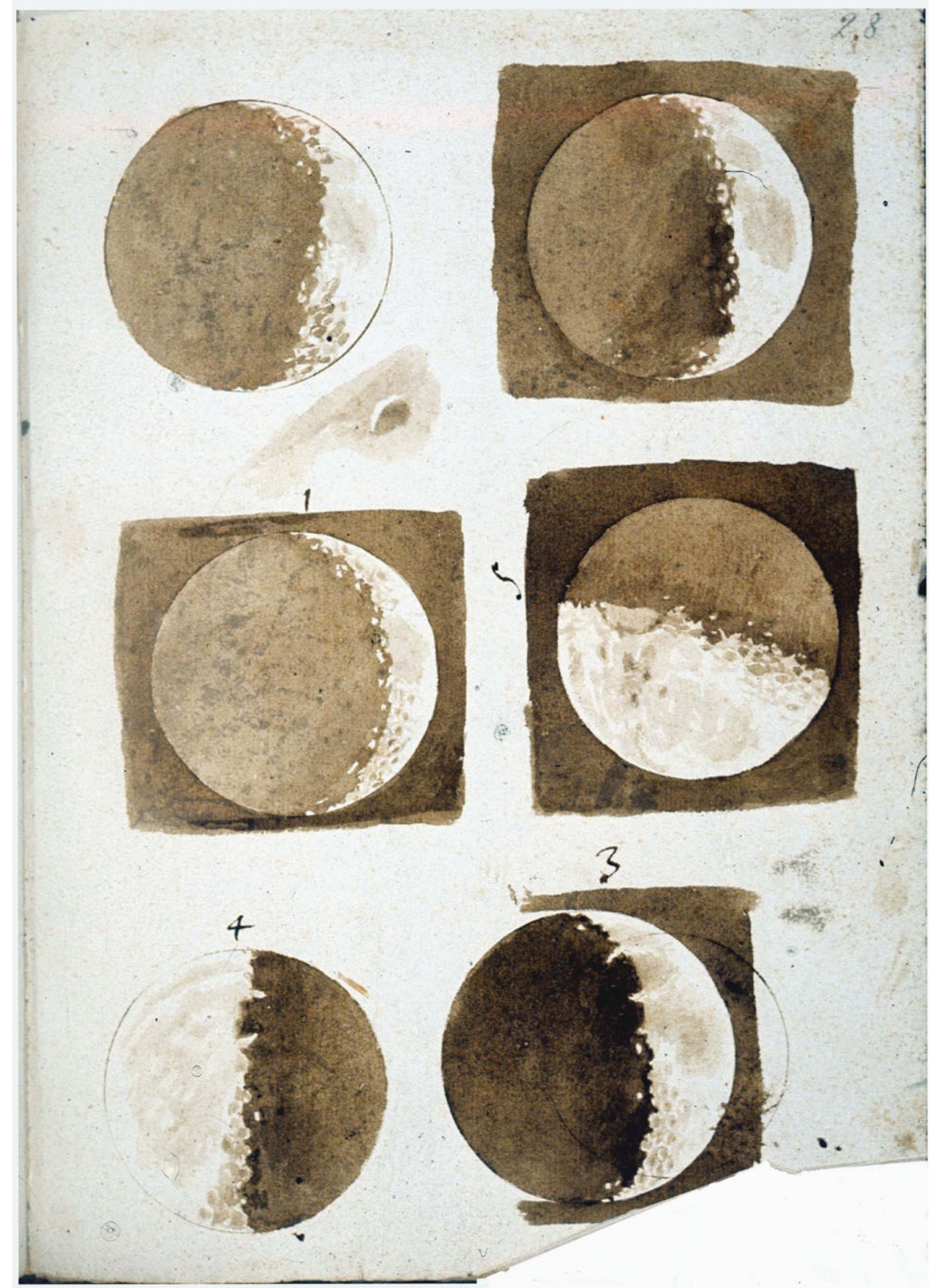

Figure 2. Galileo's Moon drawings from his Sidereus Nuncius (1610).

his first Jovian observation. This extraordinary job application not only won for him the coveted position at the Medicean court in Florence, but plunged him into international fame. It also marked the birth of telescopic astronomy.

Sidereus nuncius was not a strongly Copernican booklet, though his lunar observations were decisively anti-Aristotelian, showing that the Moon was not a pure ethereal sphere. As for the satellites of Jupiter, Galileo allowed himself a finely-tuned pro-Copernican 
argument. Some skeptics found it difficult to believe that the Earth could whirl in an annual orbit around the Sun and still keep the Moon in tow. But, Galileo pointed out, Jupiter managed to tether four moons in its twelve-year circuit around the Sun, and of course everyone agreed that Jupiter was moving. If Jupiter could do it, he implied, so could the Earth. Of course, the argument didn't prove that the Earth was moving, but it made it one notch more intellectually respectable to accept the Earth's mobility.

When Galileo was offered the court position in Florence, the question arose as to what his title would be. Galileo was quite definite that he did not want to be simply Astronomer to the Grand Duke (or in the terminology of the day, Mathematician to the Grand Duke). He much preferred Mathematician and Philosopher to the Grand Duke. Why was this so important to Galileo? Because the university astronomy professors were expected to teach about the geometry of the heavens and how to use mathematical tables to calculate the positions of the planets. But it was the philosophy professors who could speak about cosmology, how the heavens were really constructed. Galileo wanted to be credentialed to speak about cosmology, and even to attack the traditional Earth-centered Aristotelian arrangement of the heavens.

With his new, well-paid position as Mathematician and Philosopher, Galileo was keen to make all the telescopic discoveries. He tried hard to prevent Kepler from getting a powerful telescope, for instance, which almost turned out to be a serious mistake. Despite Galileo's reticence, Kepler was able to borrow a telescope from a noble friend, and to confirm the discoveries reported in the Sidereus nuncius. This came at a critical time when Galileo's discoveries were encountering some skepticism, and Galileo actually thanked Kepler for his support. But he still didn't send him a telescope. Apparently Galileo liked his sleep in the morning, and there is no evidence that he got up before dawn to observe the skies, though sometimes he stayed up after midnight to observe the waning Moon or the satellites of Jupiter. But while he was on his crash program to finish the Sidereus nuncius, he didn't look at Venus, which was bright in the pre dawn sky. After he had moved from Padua to Florence in the summer of 1610, however, Venus was moving into the evening sky, with a key discovery waiting to be made. In all probability Galileo examined Venus in the late summer, but there was little of interest. The disk of Venus was much smaller than Jupiter's, looking simply like a slightly fuzzy round dot. But early in December his former student Benedetto Castelli mentioned to him that if Venus showed phases, he might be able to distinguish between the Copernican and the Ptolemaic systems. In the Copernican system, because Venus goes around the Sun, it would show a full set of phases (as the Moon does), that is, when it was beyond the Sun, the telescope would show the fully illuminated face, whereas when it is on the near side, the telescope would show mostly the dark back side of the planet, but with a crescent of reflected sunlight. In the Ptolemaic system, the epicycle carrying Venus always lies between the Earth and Sun, so a fully illuminated face would never be visible. When Castelli's letter arrived, Galileo realized that others with telescopes could make the same test, and he might lose out on credit for another major discovery. To preserve his priority, he wrote his claims in a coded form and then scrambled the letters and sent his cryptogram to Prague, where Kepler puzzled over it. A few weeks later Galileo had enough observations in hand to be sure of the Copernican interpretation, so he sent the decipherment to Prague. Kepler promptly published (of course giving full credit to Galileo, though Galileo may have preferred to publish it himself).

While the observed phases of Venus disproved the Ptolemaic epicyclic arrangement, they did not prove the mobility of the Earth, because an alternative cosmology, proposed by Tycho Brahe, was also on the table. In the Tychonic system the Earth was solidly fixed in the center of the universe, completely immobile. The Sun moved around the 
earth, carrying t he other planets in orbit around it. Thus in the Tychonic system Venus revolved around the Sun, and would show the full gamut of phases. As Tycho wrote, "The Copernican system nowhere offends mathematics, but it throws the Earth, a lazy, sluggish body unfit for motion, into a motion as swift as the ethereal torches" (i.e., the stars). If the Earth was dizzily spinning every 24 hours, and zooming through space at several miles per second, why didn't people just fly off? Tycho complained that the Copernican system offended not only the principles of physics, but also Holy Scripture†. Tycho always registered his misgivings in that order, physics first.

In the case of Galileo, the religious issues were always near the surface, for the Catholic authorities were fighting a huge ideological battle against the Protestants north of the Alps. On cosmological issues, however, there was no warfare -the Lutherans and Calvinists agreed with the Catholics that Copernicus' treatise was a recipe book for computing the positions of planets, but it shouldn't be confused with physical reality. Nevertheless, the Catholic theologians wanted to maintain a unified front against the Protestants, and they did not want an amateur theologian interfering with that. And that was precisely the situation where Galileo found himself. His protégé Benedetto Castelli was invited to one of the brunches held by Cosimo's mother, the Grand Duchess Christina, who was undoubtedly the power behind the throne. She asked Castelli if the moons of Jupiter were real, and Castelli responded that they had been confirmed by Christopher Clavius, the leading Jesuit astronomer in Rome. "And what about the Copernican system?" she asked, "The Bible says that at the battle of Gibeon, Joshua commanded the sun, not the Earth, to stand still." "I'm sure Galileo can explain that," was Castelli's reply. This must have come as some surprise to Galileo, who hadn't concerned himself with the opinions of the Church Fathers, but he knew that, following the Council of Trent, such considerations would be required. So Galileo got tutored on Jerome and Augustine, and wrote first a reply to Castelli and then a longer response to Christina herself. He quoted a cardinal, saying that "the Bible teaches how to go to heaven, not how the heavens go." It was a very pithy way to say that the Bible is not a textbook of science, but it did not ingratiate him with the conservative theologians who were determined to defend every word of Scripture whether or not the Bible was simply speaking in common language for the common man. And thereby began a turf battle that would eventually imprison Galileo (though a battle he would eventually win when in 1984 Pope John Paul II repeated the phrase about the Bible not teaching how the heavens go and stating that Galileo was a better theologian than those he was contending with).

In 1616 Galileo journeyed to Rome in an attempt to persuade the theological hierarchy not to ban the Copernican system, lest eventually proofs of the motion of the earth would emerge. Galileo's visit alarmed the more conservative Catholic authorities, with the consequence that Copernicus' book was placed on the Index of Prohibited Books until corrected, and Galileo was notified that idea of the mobility of the Earth was contrary to Holy Scripture and could not be held or defended. Whether he was also notified that he could not teach about the Copernican system would eventually, in his trial, become a serious issue.

In 1624 a new pontiff came to the papal throne, a fellow Florentine and an acquaintance of Galileo's. In a series of audiences with the new pope, Urban VIII, Galileo became convinced that he had permission to write a book about cosmology. Galileo wrote, in a disguised dialogue form, what proved to be a brilliant vernacular defense of the Copernican system. But carried away by his enthusiasm, Galileo overplayed his hand in a

$\dagger$ After all, Psalm 104 says that the Lord God laid the foundations of the earth that they would not be moved forever. 
very stupid way: he placed the Pope's favorite argument in the mouth of a geocentrist, Simplicio, named after a sixth-century Aristotelian commentator, but all the Italians immediately recognized a pun on simpleton.

Urban VIII, undoubtedly expecting a dry, mathematical treatise comparing the geometries of the various cosmological systems, must have felt blindsided by the results, and he was furious to see his argument about God's wisdom and power placed in the mouth of Simplicio. Recounting the intricacies of Galileo's trial and its sorry outcome is beside the point of this essay, but it is worthwhile to examine the nature of Galileo's arguments, since this was a formative episode in the rise of modern science. In 1616 the leading Catholic theologian, Cardinal Bellarmine, had written a letter saying, "If there were a true demonstration that the Sun was immovable in the center of the universe, then it would be necessary to be very careful in explaining Scriptures that seem contrary. But I do not think there are any such demonstrations, since none has been shown to me. To demonstrate that the appearances are explained by assuming the motion of the Earth is not the same thing as demonstrating that in fact the Sun is in the center and the earth is moving." [abridged and partly paraphrased]

Galileo must surely have hoped to find an irrefutable physical proof for the motion of the Rarth. He thought he had come close with an argument from the tides, which he placed at the very end of his Dialogue on the Two Chief World Systems, followed by the Pope's argument (in the mouth of Simplicio) that God could have created the tides in many ways, including some beyond human intellect. If finding an irrefutable proof was a requirement, then Bellarmine and Urban VIII had won the argument.

In reality, Galileo won by altering the rules of science. What Galileo had done was to marshal a series of evidences, ranging from the observation that the moon was earthlike, that Jupiter had no problem keeping its satellites in tow, that Venus shows phases compatible with the Copernican system, that an object dropped from the mast of a moving boat will nevertheless appear to fall straight down, and so on, evidences that gave a picture coherent with a moving planet earth. It made the Copernican hypothesis no longer seem ridiculous, but something intellectually respectable. Science moves by persuasion, not by proof.

Galileo's Dialogo, while not scientifically among the most innovative texts of the astronomical revolution, was the book that won the cosmological war. In the process, Galileo had changed the rules.

\section{Epilogue}

Galileo was not the only one to argue for the compatibility of the new science with Scripture. Kepler, in the introduction to his Astronomia nova, had a fascinating defense of the heliocentric system, wherein he concluded, "If someone is so dumb that he cannot grasp the science of astronomy, or so weak that he cannot believe Copernicus without offending his piety, I advise him to mind his own business, to quit this worldly pursuit, to stay at home and cultivate his own garden, and when he turns his eyes toward the visible heavens (the only way he sees them), let him with his whole heart pour forth praise and gratitude to God the Creator. Let him assure himself that he is serving God no less than the astronomer to whom God $h$ as granted the privilege of seeing more clearly with the eyes of the mind."

No doubt Galileo read Kepler's defense, for he developed some of the same arguments in his Letter to Christina, but for an Italian Catholic to quote favorably a damned Lutheran would have been intellectual suicide. Nevertheless both astronomers were rooted in the Judeo-Christian tradition, in Jerusalem as well as Athens and Alexandria, and it was 
from this religious and philosophical foundation that their work derived. Each in their own way provided the insights that brought about the birth of modern astronomy.

\section{References}

Donahue, W. 1992, (translator) Johannes Kepler: New Astronomy (Cambridge: Cambridge University Press)

Drake S. 1987, (translator and commentator), Discoveries and Opinions of Galileo (Garden City: Doubleday)

Gingerich, G. 1993, The Eye of Heaven: Ptolemy, Copernicus, Kepler (New York: American Institute of Physics)

Gingerich, G. 1995, in Galileo a Padova 1592-1610, IV, Tribute to Galileo in Padua (Trieste: Edizioni Lint), p. 325

Van Helden, A. 1989, (translator and commentator), Galileo Galilei: Sidereus Nuncius or The Sidereal Messenger (Chicago: University of Chicago Press)

Voelkel, J. R. 2001, The Composition of Kepler's Astronomia nova (Princeton: Princeton University Press) 